\title{
On Design Inspiration for the Seismic Visitor Center Survey
}

\author{
Jinnan Hu${ }^{1}$, Ke Jia², Ying Zhang² \\ ${ }^{1}$ Yisheng College, North China University of Science and Technology, Tangshan, China \\ ${ }^{2}$ College of Architectural Engineering, North China University of Science and Technology, Tangshan, China \\ Email: 892965571@qq.com
}

How to cite this paper: Hu, J.N., Jia, K. and Zhang, Y. (2019) On Design Inspiration for the Seismic Visitor Center Survey. Open Access Library Journal, 6: e5021. https://doi.org/10.4236/oalib.1105021

Received: November 2, 2018

Accepted: May 6, 2019

Published: May 9, 2019

Copyright (c) 2019 by author(s) and Open Access Library Inc.

This work is licensed under the Creative Commons Attribution International License (CC BY 4.0).

http://creativecommons.org/licenses/by/4.0/

\section{(c) (†) Open Access}

\begin{abstract}
The Tangshan earthquake has passed for more than 40 years, but the painful memories still remain in the heart of the Tangshan people, while staying in the ruins that best reflect the current status of the earthquake-National Library of Protection Works "Library Seismic Site" of Xinhua Road Campus, North China University of Science and Technology. In order to bear the heavy pains of the Tangshan people, through the curriculum design of North China University of Technology, an "earthquake-relic site visitor center" was planned. The author conducted preliminary investigations on the Tangshan Earthquake Relics Park and the Tangshan Hero Monument: How the construction and the site environment were integrated and how the earthquake occurred. There is a certain amount of inspiration for how the commemorative nature of the dialogue took place.
\end{abstract}

\section{Subject Areas \\ Civil Engineering}

\section{Keywords}

Earthquake Site, Visitor Center, Survey Design

\section{Introduction}

This course design is a visitor center for earthquake sites. In order to better reflect the architectural spirit of the building and better integrate with the environment, it is necessary to carry out on-site investigations in the early stage. The design cannot be closed doors, we visiting the earthquake monument, $\mathrm{Nan} \mathrm{Hu}$ Earthquake Relic Park to understand the current status of seismic sites, some design examples of monumental architecture, principles of visitor center design, 
and to search for outstanding cases.

\section{Site Investigation}

The author's current research focuses on the historical background, environmental factors, traffic analysis, surrounding environment, and analysis of the site itself as examples.

\subsection{Historical Background}

The seismic area of Hebei University of Technology has a building area of 4049 square meters. The building's plane shape is a " $\mathrm{T}$ " type, divided into a reading room and a library. The three-story reading room on the south is 70 meters long, 12 meters wide, and 13.5 meters high. It can accommodate 750 people reading at the same time. Reading room is reinforced concrete beamless floor, brick wall. The museum is located $4 \mathrm{~km}$ northwest of the seismic tectonic zone and is an 11-degree crack zone within a 7.8-magnitude earthquake. It is one of the more complete cultural relics protected by the domestic heritage so far. The site is a typical example of earthquake disasters in public buildings. It can be used for teaching, research, and inspection of many disciplines such as architecture, civil engineering, material mechanics, and seismic geology. Its earthquake damage characteristics can provide examples for the study of seismic fortification of public buildings in cities. The interior of the entire building is protected by a steel frame to maintain its state at the time and is surrounded by simple fences and cordon protection. Under the impact of the earthquake wave, the library collapsed. The western part of the reading room collapsed from north to south, and the original roof collapsed and tiled to the south side of the road. The middle part falls vertically, the east gable collapses, and the main body stands upright. The first floor of the library was smashed in a strong seismic wave. Now we see the original 234 floors, and the entire building is shifted 1 meter to the east in the north and then sits down. The Hebei Earthquake Research Center was located opposite the earthquake site and was built using isolated building technology [1].

\subsection{Environmental Factors}

The ruined area is quiet, next to the school's internal transportation path, and the campus is open to the outside world, so there are some students and some old people and children sitting on stone benches.

\subsection{Traffic Analysis}

The flow of people is mainly from the southeast. Then he visited the location of the project. The location is very advantageous. There is a square in front of the library on the west side. It is a distribution center for people, with lush woods and quiet surroundings. It is a playground in the south. There is no shelter, and the view is more open. With these characteristics, the entrances and exits were 
selected to open on the eastern side of the site, and the parking lot was located in the western half of the site. The organic integration of the indoor and outdoor environments was handled, and the seismic sites were given a humble stance. A dialog was created with the initial idea of functional zoning (See Figure 1).

\section{Visit Analysis}

\subsection{Tangshan Earthquake Relics Park}

In keeping with the earthquake site of the former Tangshan Locomotive and Rolling Stock Plant, the Memorial Park [2] covers a total area of 400,000 square meters. It is adjacent to the Jingshan Railway in the west, and to Jixiang Road in the north, and is a scenic Nanshan Central City Ecological Scenic Area in the south. The park uses the railroad tracks of the original Tangshan Locomotive and Rolling Stock Works as the vertical axis to commemorate the horizontal axis of the road, and is divided into several areas such as the earthquake site area, the memorial water area, the memorial forest area and the Memorial Square. When we visit the park, we can learn that any design is a process of asking questions and solving problems. The establishment of this park needs to consider the following points:

1) How to deal with the status of earthquake sites and bases;

2) How to embody commemorative;

3) How to deal with the relationship between architecture and landscape (See Figure 2);

It is necessary to understand the base. Before the design, it is necessary to conduct a detailed inspection of the base and the surrounding environment, determine the preservation and protection, identify the conditions that can be reformed and creatively reused, and focus on the existing conditions of the base and explore potential Conditions give meaning to the building. The park has

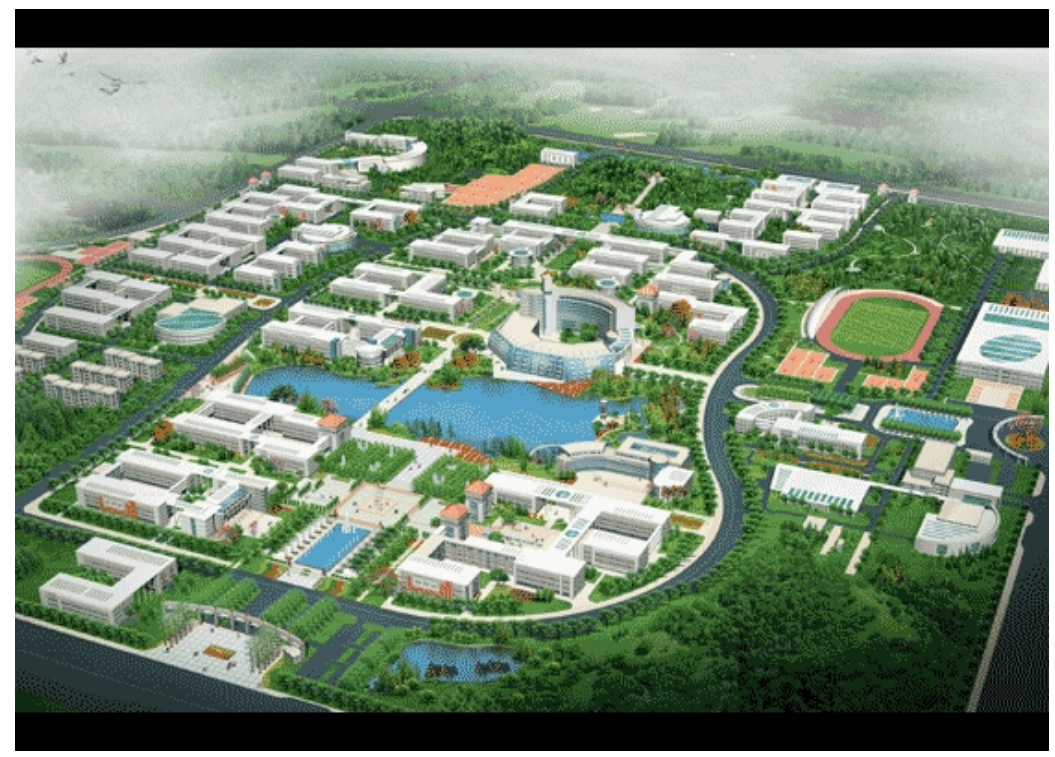

Figure 1. Traffic distinct analysis (source: Self-painting). 
achieved the unity of commemorative functions and commemorative significance and established a dialogue between architecture and landscape.

\subsection{Tangshan Earthquake Relics Park}

The monument consists of four independent trapezoidal variable-section reinforced concrete monument columns (Figure 3). The upper end of the main body has four constricted openings, which are like giant hands reaching out to the sky, symbolizing people's victory. The western part is the earthquake-resistant memorial (Figure 4). The two main buildings are located on the same axis on the east-west direction. There is a large pool between the monument and the memorial. The two buildings are connected by the floor of red brick paving. Before the monument, the shocking, spatial processing, the organization of the flow of people, the orientation of the direction is also relatively strong, and the feelings expressed by the theme park are different. It is even more inspiring and firm. Meet the needs of the provider's spiritual feelings.

Design principle: It is mainly the study of human flow, which has the following inspirations.

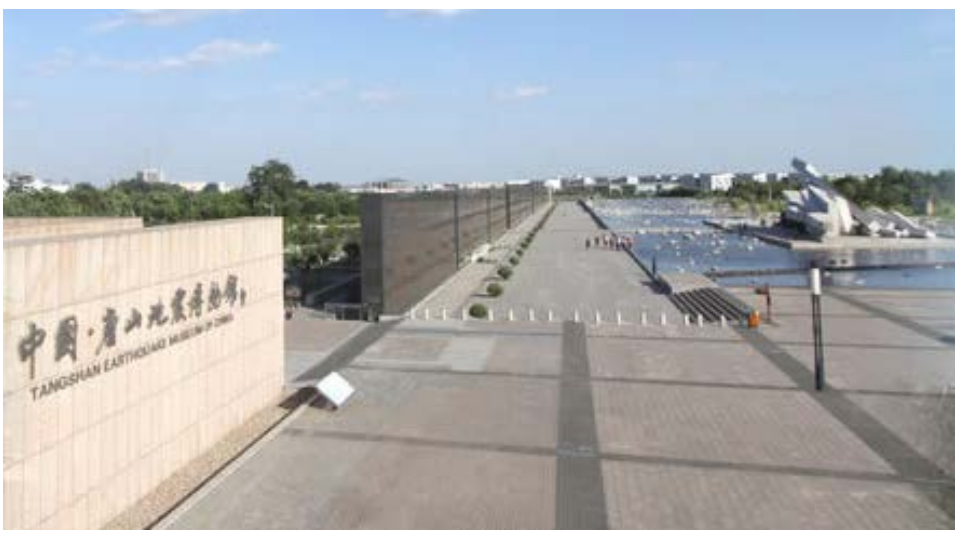

Figure 2. The relationship with architecture and landscape.

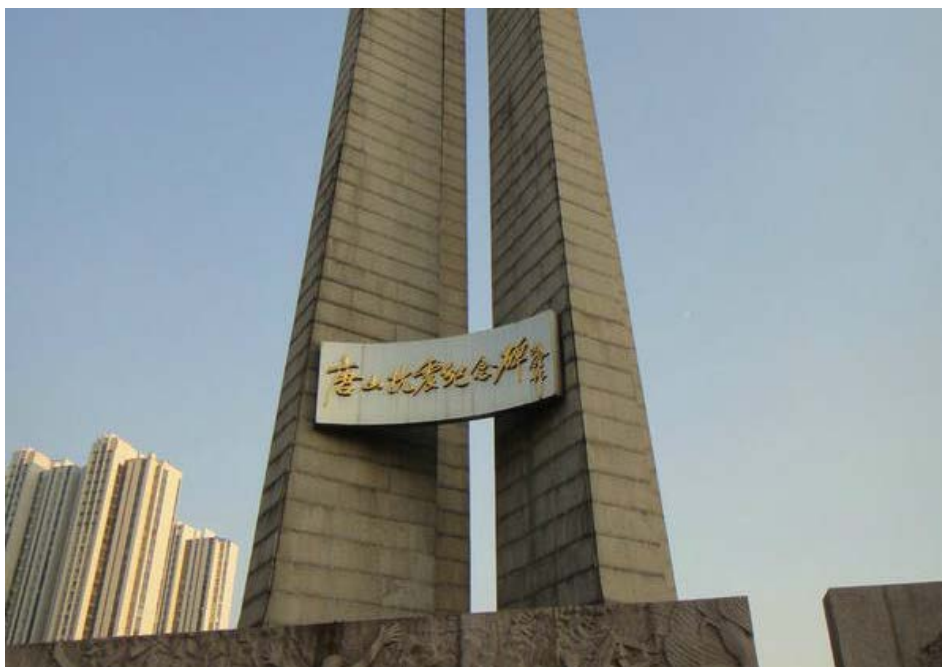

Figure 3. The monument of Tangshan Earthquake Relics Park. 


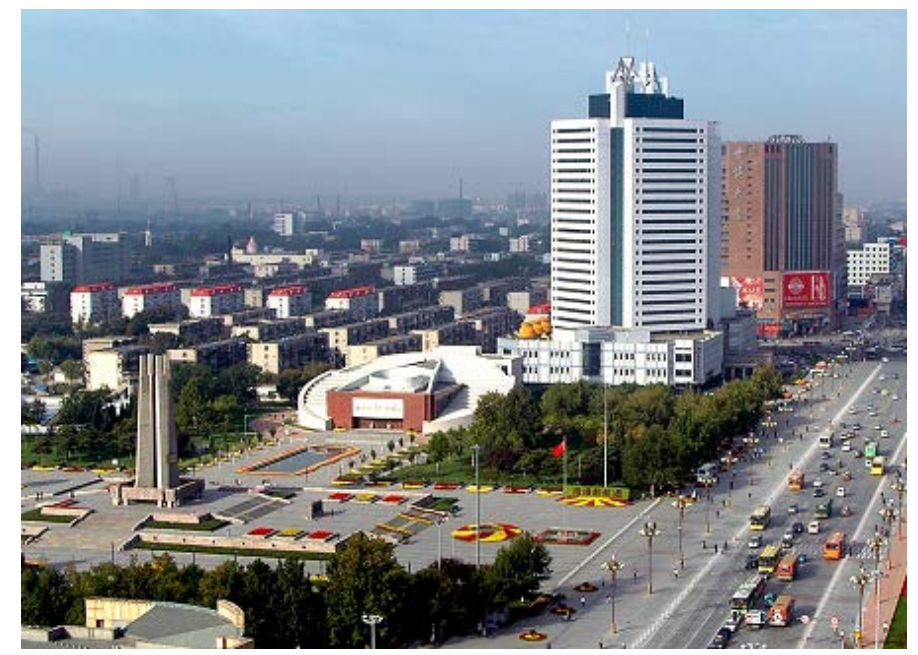

Figure 4. Earthquake-resistant memorial.

In the face of various activity rooms open to tourists, not only the activities are different, but also the way people participate in activities are different. The flow of people is frequent, showing concentration and dispersion, orderly and disorderly flow, and various different flow states.

The flow of tourists: relatively dispersed, there is no obvious peak period; the average flow of people in the lounge and exhibition halls is more dispersed and orderly.

Managers: should be able to reach the office directly and conveniently. Although there are not many people, they also need short-term, and should not be crossed with tourists. According to the characteristics of people flow, appropriate arrangements should be given in the organization of functional flow: it should be concentrated The orderly flow of people can be distributed in the shortest streamline, so that the concentrated and disordered flow of people can be controlled in areas with similar activities, to minimize interference to quiet areas of activity; It is necessary to create a streamline for freely selecting active activities when it is more convenient to use, so as to balance the flow of people to reduce the interference caused by the flow of people to and from the roundabout, and improve the utilization of equipment.

In order to control the centralized and disorderly flow of people in an area with a similar activity environment, the same kind of activity rooms can be relatively concentrated into a relatively independent area, and certain isolation measures are taken with other active environments.

\section{Conclusions}

After a series of investigations, what are we looking at? The first step is to proceed from architectural design. Architectural design refers to the design behavior for specific construction purposes, including all functional and meaningful designs in architectural behavior. It is a summary of the mental activity and performance of architectural designers. Therefore, architectural design itself emphasizes the process of thinking that comes about for a specific purpose. Our 
early thinking, research, and your final design were closely linked.

After going to the scene to find some problems or phenomenon, it needs to record and do some preliminary thinking. Afterwards, he will make some original ideas on this basis, feel the space where the base is located, discover the resources of the base, and use it. We need to clearly apply the crowd, people-oriented, and serve people. In addition, we must understand the surrounding human environment and find beneficial aspects. We must also consider unfavorable factors. We must pay attention to all the visible factors such as field research, surrounding buildings, transportation, people, and landscape.

\section{Conflicts of Interest}

The authors declare no conflicts of interest regarding the publication of this paper.

\section{References}

[1] Sogou Encyclopedia (2018) Earthquake Sites of Hebei Polytechnic University. https://baike.sogou.com/v74489891.htm?fromTitle=\%E6\%B2\%B3\%E5\%8C\%97\%E7 \%90\%86\%E5\%B7\%A5\%E5\%A4\%A7\%E5\%AD\%A6\%E5\%9C\%B0\%E9\%9C\%87\%E9 $\% 81 \% 97 \% \mathrm{E} 5 \% 9 \mathrm{D} \% 80$

[2] Sogou Encyclopedia Tangshan Earthquake Memorial (2018) https://baike.sogou.com/v610899.htm?fromTitle=\%E5\%94\%90\%E5\%B1\%B1\%E6\% 8A\%97\%E9\%9C\%87\%E7\%BA\%AA\%E5\%BF\%B5\%E7\%A2\%91 